\title{
Response-Surface-Model-Based System Sizing for Nearly/Net Zero Energy Buildings under Uncertainty
}

Sheng Zhang ${ }^{1}$, Yongjun Sun ${ }^{2}$, Yong Cheng ${ }^{3,4}$, Pei Huang ${ }^{2}$, Majeed Olaide Oladokun ${ }^{1}$, Zhang $\operatorname{Lin}^{2 *}$

( ${ }^{1}$ Department of Architecture and Civil Engineering, City University of Hong Kong, Kowloon, Hong Kong, China

${ }^{2}$ Division of Building Science and Technology, City University of Hong Kong, Kowloon, Hong Kong, China

${ }^{3}$ National Centre for International Research of Low-carbon and Green Buildings, Ministry of Science \& Technology, Chongqing University, Chongqing, China ${ }^{4}$ Joint International Research Laboratory of Green Buildings and Built Environments, Chongqing University, Chongqing, China

*Corresponding author. Tel.: +852 34429805; fax: +852 34429716; E-mail: bsjzl@cityu.edu.hk)

\begin{abstract}
Properly treating uncertainty is critical for robust system sizing of nearly/net zero energy buildings (ZEBs). To treat uncertainty, the conventional method conducts Monte Carlo simulations for thousands of possible design options, which inevitably leads to computation load that is heavy or even impossible to handle. In order to reduce the number of Monte Carlo simulations, this study proposes a response-surface-modelbased system sizing method. The response surface models of design criteria (i.e., the annual energy match ratio, self-consumption ratio and initial investment) are established based on Monte Carlo simulations for 29 specific design points which are determined by Box-Behnken design. With the response surface models, the overall performances (i.e., the weighted performance of the design criteria) of all design options (i.e., sizing combinations of photovoltaic, wind turbine and electric storage) are evaluated, and the design option with the maximal overall performance is finally
\end{abstract}


Applied Energy

Volume 228, 15 October 2018, Pages 1020-1031

selected. Cases studies with 1331 design options have validated the proposed method for 10,000 randomly produced decision scenarios (i.e., users' preferences to the design criteria). The results show that the established response surface models reasonably predict the design criteria with errors no greater than $3.5 \%$ at a cumulative probability of $95 \%$. The proposed method reduces the number of Monte Carlos simulations by $97.8 \%$, and robustly sorts out top $1.1 \%$ design options in expectation. With the largely reduced Monte Carlo simulations and high overall performance of the selected design option, the proposed method provides a practical and efficient means for system sizing of nearly/net ZEBs under uncertainty.

Keywords: Response surface model; Monte Carlo simulation; System sizing; Zero energy building; Uncertainty

\section{Introduction}

Nearly/net zero energy buildings (ZEBs) remain as promising solutions to the increasing energy and environment problems $[1,2]$. Buildings account for about $40 \%$ primary energy and $24 \% \mathrm{CO}_{2}$ emission worldwide [3]. Nearly/net ZEBs are characterized by a high degree of energy autonomy [4, 5]. With reduced energy consumption by energy efficient technologies (e.g., ground source heat pumps [6, 7] and thermal driven cooling systems [8]), nearly/net ZEBs are configured with the renewable energy system to achieve a targeted annual energy match ratio (AEMR) [9, 10]. By definition, AEMR is the ratio of annual energy generation from the renewable energy system to annual energy consumption of buildings [11, 12]. AEMR of a net ZEB is targeted at $100 \%$, and that of a nearly ZEB is allowed to be less than $100 \%$ but larger than the minimal value stipulated by the policy $[13,14]$.

When designing a nearly/net ZEB, it is challenging to properly size the renewable energy system with multiple and mutually contradictory design criteria [14, 15]. Design 
Applied Energy

Volume 228, 15 October 2018, Pages 1020-1031

optimization of the renewable energy system stands as one of the major concerns in the field of nearly/net ZEBs [14]. While an under-sized renewable energy system fails to fulfill the requirements on AEMR [16], an over-sized renewable energy system leads to an unnecessary increase in its initial investment. Meanwhile, a properly sized renewable energy system is supposed to minimize the grid stress caused by the energy interaction between the nearly/net ZEBs and grid $[17,18]$. Due to the intermittent and fluctuant renewable energy generation and building energy consumption, nearly/net ZEBs dynamically export the surplus energy generation to the grid and import the complementary energy from the grid. To mitigate the grid stress, the renewable energy system is desired to be sized with a high self-consumption ratio (SCR) $[18,19]$. SCR is the percentage of the annual renewable energy generation consumed directly by the nearly/net ZEBs [20, 21]. A smaller size of the renewable energy generation device could elevate SCR, but decrease AEMR, and a larger size of the renewable energy storage device could elevate SCR, but increase the initial investment.

Common methods size the renewable energy system for nearly/net ZEBs in a deterministic manner [22, 23]. Firstly, the building energy generation and consumption are estimated under the worst scenario or standard scenario with a safety factor [24]. Thus, the building energy generation is under-estimated and the building energy consumption is over-estimated. Secondly, the renewable energy system is sized based on the under-estimated building energy generation and over-estimated building energy consumption. As a result, the renewable energy system is commonly oversized, with unnecessarily high initial investment and a low SCR $[24,25]$. On the other hand, the building energy generation and consumption are vulnerable to uncertainties associated with weather, building physical properties and etc. [26, 27]. Due to these uncertainties, the actual performance of a nearly/net ZEB sized from the deterministic methods could deviate significantly from the designed performance [28, 29]. For example, the real operation of an occupied ZEB in China was reported by Zhou et al [30] that the annual 
Applied Energy

Volume 228, 15 October 2018, Pages 1020-1031

energy consumption was larger than the designed value by $30.9 \%$ and the annual energy generation was smaller than the designed value by $36.8 \%$. Attia et al. [31] comprehensively analyzed the present situations of seven European countries and pointed out that the treatment of uncertainty was a future challenge for the design of nearly/net ZEBs.

To address the problems above, the multi-criteria system sizing method for nearly/net ZEBs under uncertainty was proposed by Zhang et al. [16] and Sun et al. [29]. The multiple design criteria were weighted according to users' preference. Uncertainties in the physical, design and scenario parameters were treated with Monte Carlo simulations. An improvement of $44 \%$ in the overall performance by the optimization was reported [16]. This method was further improved by Yu et al. [32] to achieve a user-defined confidence level of the designed performance. Also, Lu et al. [15] quantified the actual performance of a nearly/net ZEB in different years under uncertainty with Monte Carlo simulations, and identified the relationship between the probability to achieve the actual performance and designed AEMR. These methods could comprehensively make tradeoffs among the conflicting design criteria and harvest robust design. However, they faced a limitation of excessive computation load due to the large number of Monte Carlo simulations [33]. Monte Carlo simulations are the main technology used to treat uncertainty in the field of building energy $[34,35]$. To achieve the robust design of nearly/net ZEBs, existing methods conducted Monte Carlos simulations for thousands of design options [15, 16, 29]. For instance, Lu et al. [15] repeated 500-years Monte Carlo simulations for 2457 different design options of the renewable energy system. That is, the annual energy consumption and generation simulations of the nearly/net ZEB were repeated by $1,228,500$ times (i.e., $500 \times 2457$ ).

To reduce the number of Monte Carlo simulations for nearly/net ZEB design under uncertainty, this paper proposes a response-surface-model-based system sizing method. The response surface methodology is an easy-to-use meta-modeling technique, which 
Applied Energy

Volume 228, 15 October 2018, Pages 1020-1031

can identify the relationship between a design response and a set of design parameters based on a limited number of controlled experiments/simulations [36, 37]. The identified relationship (i.e., the response surface model) reveals the effects of the design parameters on the design response. So that the design parameters could be optimally determined to achieve the most desirable design response, requiring no more experiments/simulations. The response surface methodology has been applied to the building environment design for indoor air quality and thermal comfort, such as the design of natural ventilation [38, 39], underfloor air distribution [40], impinging jet ventilation [41] and other mechanical ventilation modes [42,43]. The response surface methodology has also been employed to model the building energy consumption for improved energy efficiency, including passive retrofit optimization [44], window geometry optimization [45], exergy optimization of the cooling tower [46] and optimal control of the variable refrigerant flow system [47]). However, it is unknown whether the response surface methodology could function satisfactorily for nearly/net ZEBs, due to the increased complexities from interactions among the renewable energy system, building energy consumption system and grid [14]. Kneifel et al. [48] reported that it was challenging for the meta-models to accurately predict the energy performances of nearly/net ZEBs without considering the uncertainty. Moreover, uncertainty analysis also contributes to the complexities of nearly/net ZEB design [29], which further challenges the application of the response surface methodology.

In this study, the response surface methodology will be employed to identify the relationship between the size of the renewable energy system (including photovoltaic (PV), wind turbine (WT) and electric storages $[16,32])$ and each design criterion (i.e., AEMR, SCR and initial investment [16]). With the response surface models, the overall performances (i.e., the weighted performance of AEMR, SCR and initial investment) of all the design options are calculated for decision making purposes. The establishment of the response surface models requires Monte Carlo simulations for only 29 specific 
Applied Energy

Volume 228, 15 October 2018, Pages 1020-1031

design points. As a consequence, the proposed method largely reduces the number of Monte Carlo simulations, when compared with the conventional method conducting Monte Carlo simulations for thousands of design options [16, 29].

With the largely reduced Monte Carlo simulations, the primary concern of the proposed response-surface-model-based system sizing method is that whether it can sort out the design option with high overall performance. This study first introduces and explains the proposed response-surface-model-based system sizing method for nearly/net ZEBs under uncertainty (Section 2). Case studies are then conducted to demonstrate the effectiveness and robustness of the proposed method in sorting out the design option with high overall performance (Section 3). The case studies consider 10,000 decision scenarios (i.e., users' preferences to the design criteria). The users' preferences in practice can significantly affect the overall performance of the finally selected design option [25]. Thus, different users' preferences should be taken into consideration to ensure the robustness of the proposed method. Lastly, several application issues of the proposed method are discussed in Section 4.

There are two main contributions of this study. (1) The response surface methodology is confirmed to work satisfactorily for the energy performances of nearly/net ZEBs. Compared with other meta-modeling techniques (e.g., the one used in Reference [48]), the response surface methodology can generate more accurate meta-models requiring fewer data due to the utilization of the methods of Design of Experiment [50]. The effectiveness of the response surface methodology needs to be tested for different applications. Many studies are focusing on testing the response surface methodology for a specific application (e.g., modeling the thermal environment of natural ventilation [39], displacement ventilation [40], impinging jet ventilation [41] and task/ambient air conditioning system [51]). This is the first time for the response surface methodology to be tested for the energy performances of nearly/net ZEBs. (2) This study proposes a method which can substantially reduce the number of Monte Carlo simulations and 
Applied Energy

Volume 228, 15 October 2018, Pages 1020-1031

robustly sort out the optimal design option. Existing methods [15, 16, 29] for the robust system sizing of nearly/net ZEBs conducted Monte Carlos simulations for thousands of design options, leading to computational load that is heavy or even impossible to handle for practical applications. The proposed method conducts Monte Carlos simulations only for 29 specific design points. Thus, this study provides a practical and efficient means for system sizing of nearly/net ZEBs under uncertainty.

\section{Methodology}

\subsection{Overview of proposed response-surface-model-based system sizing method}

Figure 1 shows the proposed response-surface-model-based system sizing method for nearly/net ZEBs under uncertainty. It includes three main parts: (1) to determine the design points using Box-Behnken design; (2) to calculate the response values of each design criterion for the determined design points by running Monte Carlo simulations; and (3) to establish the response surface model for each design criterion based on the calculated response values, and to evaluate the overall performances of all design options for the decision making using the established response surface models.

The response surface model is a polynomial regression model representing the relationship between the design criteria and the design parameters (Equation 1 with second order) [36]. The coefficients $\left(\beta_{o}, \beta_{p}, \beta_{p p}\right.$ and $\left.\beta_{p q}\right)$ in Equation 1 can be identified by the multiple regression technique. To increase the accuracy of the response surface models, the collinearity of the design points needs to be reduced. The collinearity can be reduced by increasing the orthogonality of the design points with Design of Experiment methods [39, 41]. As one of the most widely used Design of Experiment methods, Box-Behnken design is employed in this study [38, 46]. Design Expert software can be directly used to make the response surface modeling userfriendly [52]. 


\section{Applied Energy}

Volume 228, 15 October 2018, Pages 1020-1031

$$
y=\beta_{o}+\sum_{p=1}^{k} \beta_{p} x_{p}+\sum_{p=1}^{k} \beta_{p p} x_{p}^{2}+\sum_{p=1}^{k} \sum_{q>i}^{k} \beta_{p q} x_{p} x_{q}
$$

where $y$ is the response parameter (i.e., the design criterion) or the transformation of the response parameter (e.g., transformation of natural log and square root $[52,53]) ; \beta_{o}$, $\beta_{p}, \beta_{p p}$ and $\beta_{p q}$ are the coefficients; $x_{p}$ and $x_{q}$ are the $p^{\text {th }}$ and $q^{\text {th }}$ design parameters respectively, and totally there are $k$ different design parameters. 


\section{Applied Energy}

Volume 228, 15 October 2018, Pages 1020-1031
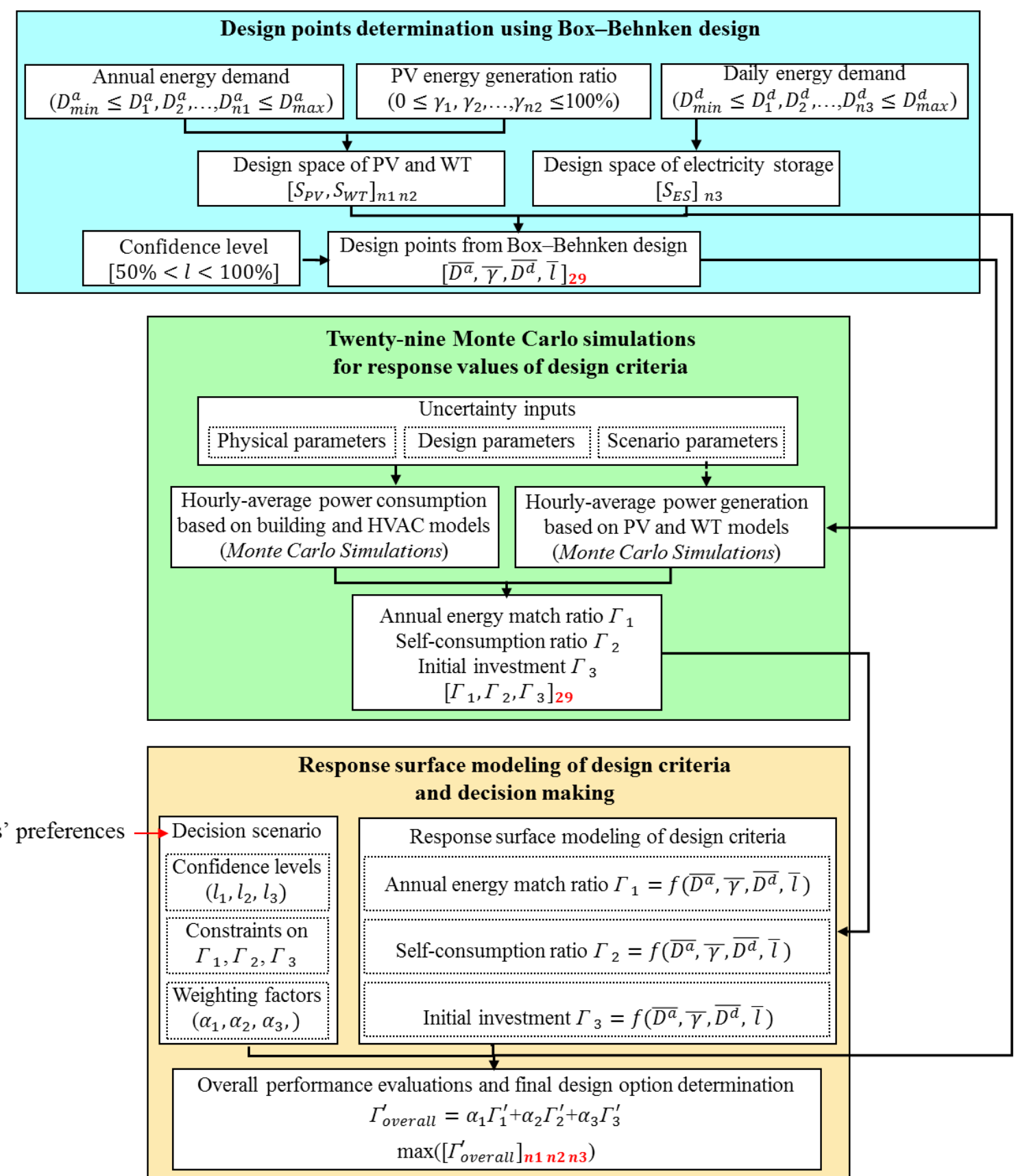

Fig.1. Schematic diagram of response-surface-model-based system sizing method for nearly/net ZEBs under uncertainty.

\subsection{Design points determination using Box-Behnken design}

Design points for establishing response models are selected from the design space and the allocated confidence levels. In this study, the renewable energy system consists of 
PV and WT and electric storage [32]. Sizes of PV and WT are selected according to building annual energy demand $\left(D^{a} k W h\right)$ and renewable energy generation percentage of PV ( $\gamma \%)$ (Equations 2 and 3) [16]. The energy generation percentage of PV is defined as a ratio of the energy generated annually by PV to the annual energy generation of the building. Hence, the design space of PV and WT is determined by all combinations of the annual energy demand and energy generation percentage of PV (i.e., $n_{1} \times n_{2}$ in Figure 1). The lower and upper limits of the annual energy demand ( $D_{\min }^{a} k W h, D_{\max }^{a} k W h$ ) can be identified either based on the statistical characteristics of the annual energy demand (Equations 4 and 5) [42] or using the worst scenario method [16]. The electric storage is sized to achieve short-term grid independence (e.g., from several hours to days), and its size is suggested to be equivalent to one to three times of the daily energy demand [54-56]. In order to cover the recommended sizing range, the design space of the electric storage is set to from one half of the daily energy demand to four times of the daily energy demand. The confidence level $(l \%)$ means the cumulative probability to achieve the designed performance in a selected criterion. The confidence level is limited within 50 100\%.

$$
\begin{gathered}
S_{P V}=\frac{\gamma D^{a}}{G_{P V}^{a}} \\
S_{W T}=\frac{(1-\gamma) D^{a}}{G_{W T}^{a}}
\end{gathered}
$$

where $D^{a}(k W h)$ is the annual energy demand of the nearly/net ZEB; $G_{P V}^{a}$ $\left(k W h / m^{2}\right)$ and $G_{W T}^{a}(k W h / k W)$ are the annual energy generation from PV of one square meter and WT with a rated power of one kilowatt respectively; $\gamma(\%)$ is the energy generation percentage of PV; $S_{P V}\left(m^{2}\right)$ and $S_{W T}(k W)$ are the area of PV and rated power of WT respectively.

$$
\begin{gathered}
D_{\text {max }}^{a}=\mu_{D^{a}}+c \sigma_{D^{a}} \\
D_{\text {min }}^{a}=\mu_{D^{a}}-c \sigma_{D^{a}}
\end{gathered}
$$

where $D_{\min }^{a}(k W h)$ and $D_{\max }^{a}(k W h)$ are the minimal and maximal values of the annual energy demand of a nearly/net ZEB respectively; $\mu_{D^{a}}(k W h)$ and $\sigma_{D^{a}}(k W h)$ 
Applied Energy

Volume 228, 15 October 2018, Pages 1020-1031

are the mean value and standard deviation of the annual energy demand distribution respectively; $c$ is a constant.

To determine the design points, the Box-Behnken design is used. First, all design parameters are coded into $-1 \sim 1$ (Equation 6), and three levels for each design parameter are defined: -1 for low level, 0 for medium level and 1 for high level. Then, BoxBehnken design determines the design points in a way to avoid extreme design conditions where all the design parameters are at high/low levels simultaneously. For instance, Figure 2 shows the geometry of Box-Behnken design with three design parameters $\left(X_{1}, X_{2}\right.$ and $\left.X_{3}\right)$ [41]. The design points are selected at each edge and the central point rather than the corners, because the corners represent extreme conditions. The number of design points using Box-Behnken design is determined by the number of design parameters and repetitive number of the central design point (Equation 7). The central design point is repeated to account for errors caused by the experiments/simulations [36].

$$
\bar{x}=\frac{2\left(x-x_{\min }\right)}{x_{\max }-x_{\min }}-1
$$

where $\bar{x}$ is the coded value (i.e., normalized value) of the design parameter; $x$ is the original value of the design parameter; $x_{\min }$ and $x_{\max }$ are the minimal and maximal original values of the design parameter.

$$
N=2 k(k-1)+C
$$

where $C$ is the repetitive number of the central design point; $k$ is the number of the design parameters; and $N$ is the number of the design points determined by BoxBehnken design. 


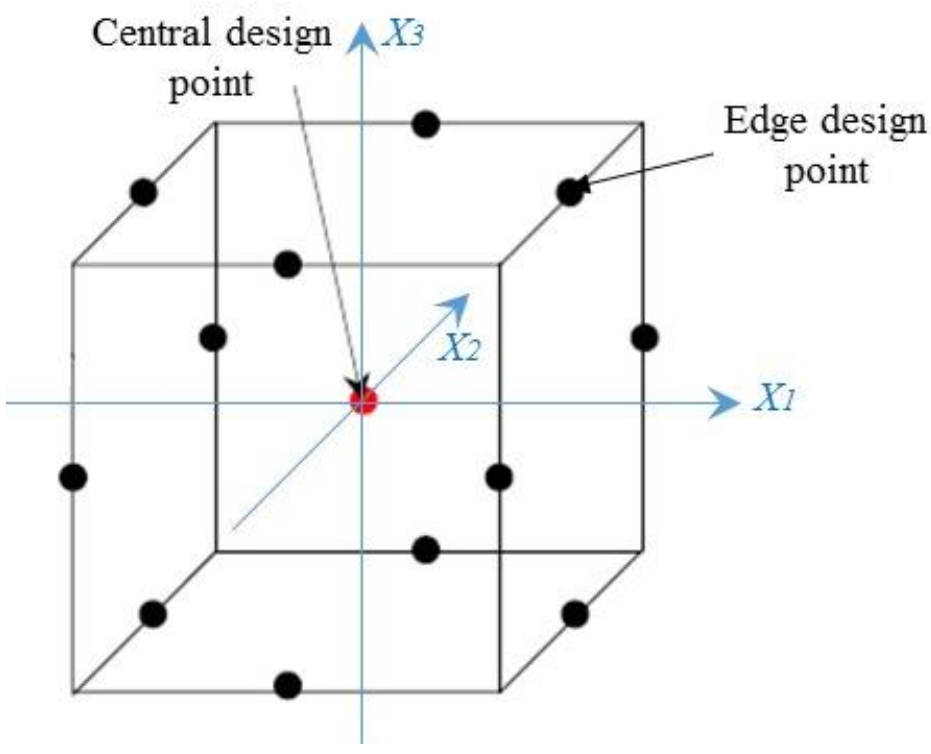

Fig.2. Demonstration of design point determination using Box-Behnken design: geometry of design points with three design parameters.

\subsection{Monte Carlo simulations for response values of design criteria}

The response values of the design criteria for the design points from Box-Behnken design (Section 2.2) are calculated based on 400-year Monte Carlo simulations [16]. Monte Carlo simulations are employed to produce the hourly building energy generation and consumption, as three types of input parameter uncertainties are considered (Table 1). Physical parameters refer to physical properties of building materials. Design parameters refer to pre-set working conditions during the planning process. Scenario parameters refer to real-time operations [57]. The scenario parameters of wind velocity and solar radiation are the primary sources of uncertainty for WT energy generation and PV energy generation respectively [59]. Wind velocity and solar radiation are quantified to follow Rayleigh distribution [60] (simplified from Weibull distribution [61]) and normal distribution [62] respectively. Parameter uncertainties associated with the building energy consumption are quantified using statistical distributions as presented in Table 1. Truncation and rounding are conducted to make the parameters from the statistical distributions realistic [29]. Since Monte 


\section{Applied Energy}

Volume 228, 15 October 2018, Pages 1020-1031

Carlo simulations have been widely used to treat the uncertainty for the robust design of buildings [33], the detailed process of Monte Carlo simulations are not given in this study but can be found in References [16, 29].

Table 1. Parameter-uncertainty distributions affecting building energy consumption.

\begin{tabular}{|c|c|c|c|c|}
\hline $\begin{array}{l}\text { Uncertainty } \\
\text { type }\end{array}$ & Parameter & $\begin{array}{c}\text { Distribution } \\
\text { type }\end{array}$ & $\begin{array}{l}\text { Base } \\
\text { value }\end{array}$ & Distribution \\
\hline \multirow{5}{*}{$\begin{array}{c}\text { Physical } \\
\text { parameters } \\
{[29,63,64]}\end{array}$} & $\begin{array}{l}\text { U value of window } \\
\left(\mathrm{kJ} /\left(\mathrm{hm}^{2} \mathrm{~K}\right)\right)\end{array}$ & $\begin{array}{l}\text { Normal } \\
\text { distribution }\end{array}$ & 8.17 & $\mathrm{~N}\left(8.17,0.4^{2}\right)$ \\
\hline & $\begin{array}{l}\text { Internal shading } \\
\text { coefficient }\end{array}$ & $\begin{array}{l}\text { Normal } \\
\text { distribution }\end{array}$ & 0.5 & $\mathrm{~N}\left(0.5,0.1^{2}\right)$ \\
\hline & $\begin{array}{l}\text { External shading } \\
\text { coefficient }\end{array}$ & $\begin{array}{l}\text { Normal } \\
\text { distribution }\end{array}$ & 0.2 & $\mathrm{~N}\left(0.2,0.05^{2}\right)$ \\
\hline & $\begin{array}{l}\text { Internal conductive heat } \\
\text { transfer rate }\left(\mathrm{kJ} /\left(\mathrm{hm}^{2} \mathrm{~K}\right)\right)\end{array}$ & $\begin{array}{l}\text { Normal } \\
\text { distribution }\end{array}$ & 11 & $\mathrm{~N}\left(11,0.5^{2}\right)$ \\
\hline & $\begin{array}{l}\text { External conductive heat } \\
\text { transfer rate }\left(\mathrm{kJ} /\left(\mathrm{hm}^{2} \mathrm{~K}\right)\right)\end{array}$ & $\begin{array}{l}\text { Triangular } \\
\text { distribution }\end{array}$ & 68.4 & $\mathrm{~T}(43.2,68.4,82.8)$ \\
\hline \multirow{5}{*}{$\begin{array}{c}\text { Design } \\
\text { parameters } \\
{[29,64,65]}\end{array}$} & Occupant number & $\begin{array}{l}\text { Normal } \\
\text { distribution }\end{array}$ & 16 & $\mathrm{~N}\left(16,2^{2}\right)$ \\
\hline & Computer number & $\begin{array}{l}\text { Normal } \\
\text { distribution }\end{array}$ & 16 & $\mathrm{~N}\left(16,3^{2}\right)$ \\
\hline & Light ratio & $\begin{array}{l}\text { Normal } \\
\text { distribution }\end{array}$ & 1 & $\mathrm{~N}\left(1,0.2^{2}\right)$ \\
\hline & Infiltration $(\mathrm{ACH})$ & $\begin{array}{l}\text { Normal } \\
\text { distribution }\end{array}$ & 0.2 & $\mathrm{~N}\left(0.2,0.05^{2}\right)$ \\
\hline & Ventilation $(\mathrm{ACH})$ & $\begin{array}{l}\text { Normal } \\
\text { distribution }\end{array}$ & 10 & $\mathrm{~N}\left(10,0.5^{2}\right)$ \\
\hline \multirow{2}{*}{$\begin{array}{c}\text { Scenario } \\
\text { parameters } \\
{[29,66,67]}\end{array}$} & Ambient temperature $\left({ }^{\circ} \mathrm{C}\right)$ & $\begin{array}{l}\text { Normal } \\
\text { distribution }\end{array}$ & TMY & $\mathrm{N}\left(\mathrm{TMY}, 0.01 \mathrm{TMY}^{2}\right)$ \\
\hline & $\begin{array}{l}\text { Ambient relative humidity } \\
(\%)\end{array}$ & $\begin{array}{l}\text { Normal } \\
\text { distribution }\end{array}$ & TMY & $\mathrm{N}\left(\mathrm{TMY}, 0.01 \mathrm{TMY}^{2}\right)$ \\
\hline
\end{tabular}

Note: ACH is air change per hour [25]; TMY represents hourly data from the typical meteorology year; the base values are from Reference [29].

The design criteria of nearly/net ZEBs include AEMR, SCR and initial investment of the renewable energy system $[11,16]$. Equations 8 and 9 describe the calculations of 
AEMR and SCR of the $j^{\text {th }}$ year from the hourly building energy generation and consumption respectively. A confidence level is used to describe the cumulative probability of achieving the designed performance in a selected criterion during the 400-year Monte Carlo simulations. For instance, an AEMR with a value of $\mathrm{AEMR}_{l}$ and a confidence level of $l$ means that the cumulative probability for AEMR of 400year Monte Carlo simulations to be larger than the value of $\mathrm{AEMR}_{l}$ is $l$ (Figure 3). The initial investment is calculated by Equation 10 [32].

$$
\begin{aligned}
& A E M R_{j}=\frac{\sum_{i=8760(j-1)+1}^{8760 j}\left(\text { Pow }_{P V, i j}+\text { Pow }_{W T, i j}\right)}{\sum_{i=8760(j-1)+1}^{8760 j} \text { Pow }_{c o n, i j}} \times 100 \% \\
& S C R_{j}=\frac{\sum_{i=8760(j-1)+1}^{8760 j}\left(\operatorname{Pow}_{P V, i j}+P o w_{W T, i j}-\Delta E S_{i j}-E I_{i j}\right)}{\sum_{i=8760(j-1)+1}^{8760 j}\left(\operatorname{Pow}_{P V, i j}+P w_{W T, i j}\right)} \times 100 \%
\end{aligned}
$$

where $A E M R(\%)$ is the annual energy match ratio; EI $(\mathrm{kW})$ is the energy exporting to the grid $(E I>0) ; \operatorname{Pow}_{P V}(k W)$ and $\operatorname{Pow}_{W T}(k W)$ are the hourly-average power generation from installed PV and WT respectively; SCR (\%) is the self-consumption ratio; $\triangle E S(k W)$ is the variation of stored electricity in the electric storage, and larger than zero when the stored electricity increases; subscripts $i$ and $j$ are $i^{\text {th }}$ hour and $j^{\text {th }}$ year respectively.

$$
I I=\rho_{P V} S_{P V}+\rho_{W T} S_{W T}+\rho_{E S} S_{E S}
$$

where $I I(H K D)$ is the initial investment of the renewable energy system; $S_{E S}(k W h)$, $S_{P V}\left(\mathrm{~m}^{2}\right)$ and $S_{W T}(\mathrm{~kW})$ are the capacity of the electric storage, area of PV and rated power of WT respectively; $\rho_{E S}(H K D / k W h), \rho_{P V}\left(H K D / m^{2}\right)$ and $\rho_{W T}(H K D /$ $k W)$ are the unit price of the electric storage, PV and WT respectively. 
Applied Energy

Volume 228, 15 October 2018, Pages 1020-1031

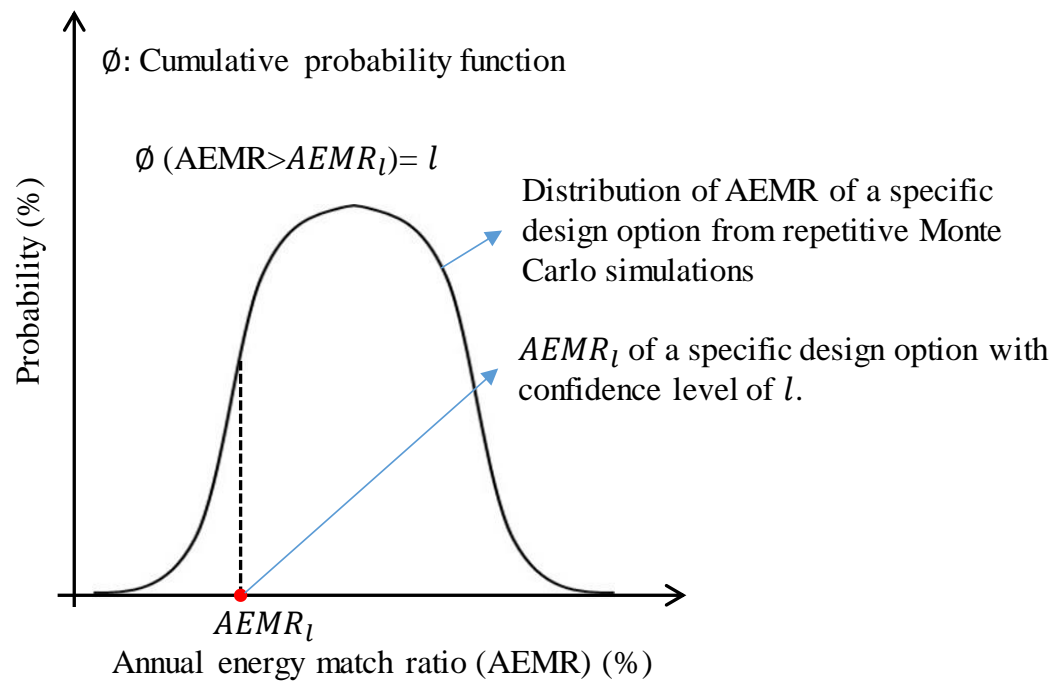

Fig.3. Usage demonstration of confidence level: AEMR determination with a specific confidence level.

\subsection{Response surface modeling of design criteria and decision making}

Response surface models of AEMR and SCR (Equation 1) are established based on the determined design points (Section 2.2) and corresponding response values from Monte Carlo simulations (Section 2.3). The least square method is used to identify the coefficients in Equation 1 for AEMR and SCR, and the backward elimination procedure is used to enhance the data fit by reducing insignificant terms [39, 68]. Firstly, a full model including all terms in Equation 1 is established by multiple regression analysis with the least square method. Then, the partial probability values (P-value) of included terms are estimated by ANOVA (i.e., Analysis of Variance) tests. Lastly, the terms with P-values higher than 0.05 (indicating statistically insignificant terms) are removed. The quality of the response surface models can be evaluated by comparison with Monte Carlo simulations for the design points which are not involved in the model establishment [36]. The initial investment is assumed to be determined by the size of the renewable energy system [32]. Thus the response surface model of the initial investment is the same as Equation 10. 
The response-surface-model-based decision making is as follows. Firstly, for all design options of the renewable energy system from the design space (i.e., $n_{1} \times n_{2} \times n_{3}$ in Figure 1), the values of $\operatorname{AEMR}\left(\Gamma_{1}\right), \operatorname{SCR}\left(\Gamma_{2}\right)$ and initial investment $\left(\Gamma_{3}\right)$ are calculated using the obtained response surface models and user-defined confidence levels. Secondly, the user-defined constraints (i.e., lower/upper limits) on each design criterion are used to exclude the design options failing to meet the constraints, by determining the corresponding overall performance as zero. Thirdly, values of design criteria of the remaining design options are normalized as Equation 11, and the overall performances are evaluated with user-defined weighting factors (Equation 12) [16, 69]. Lastly, the design option with the maximal overall performance is selected as the optimal one.

$$
\Gamma^{\prime}=\frac{\Gamma-\Gamma_{\text {least }}}{\Gamma_{\text {most }}-\Gamma_{\text {least }}} \times 100 \%
$$

where $\Gamma^{\prime}$ is the normalized value of a design criterion; $\Gamma$ is the value of a design criterion; $\Gamma_{\text {least }}$ and $\Gamma_{\text {most }}$ are the worst and best performance respectively.

$$
\Gamma_{\text {overall }}^{\prime}=\alpha_{1} \Gamma_{1}^{\prime}+\alpha_{2} \Gamma_{2}^{\prime}+\alpha_{3} \Gamma_{3}^{\prime}
$$

where $\Gamma_{\text {overall }}^{\prime}$ is the overall performance of a specific design option; $\Gamma_{1}^{\prime}, \Gamma_{2}^{\prime}$ and $\Gamma_{3}^{\prime}$ are the normalized value of AEMR, SCR and initial investment respectively; $\alpha_{1}, \alpha_{2}$ and $\alpha_{3}$ are the weighting factors assigned to AEMR, SCR, and initial investment respectively, and their sum is one.

\section{Case studies}

\subsection{Simulation models of the nearly/net ZEB}

TRNSYS [70] is used to establish the simulation platform for a nearly/net ZEB (Figure 4). This simulation platform has been used for several studies of the design of nearly/net ZEBs $[16,29,32]$. Here, for readability, the simulation models are briefly described as follows, and more detailed descriptions are given by References [16, 29, 32]. The nearly/net ZEB is a ten-storey academic building (Type 56) located in subtropical Hong Kong. Each storey is configured with two identical classrooms $(7.6 \mathrm{~m} \times 6 \mathrm{~m} \times 3 \mathrm{~m})$. One room has one west-facing window of $4 \mathrm{~m} \times 1.5 \mathrm{~m}$, and is equipped with 16 
Applied Energy

Volume 228, 15 October 2018, Pages 1020-1031

computers with a nominal power of $140 \mathrm{~W}$ of each, and eight halogen lights with a rated power of $55 \mathrm{~W} / \mathrm{m}^{2}$ of each. Sixteen occupants stay in the room from 6 am to 10 $\mathrm{pm}$. To provide a satisfactory indoor environment, the room temperature and relative humidity are set at $25^{\circ} \mathrm{C}$ and $50 \%$ respectively $[71,72]$. The infiltration rate is assumed to be $0.2 \mathrm{ACH}$. Other main parameters of the building model are listed in Table 1.

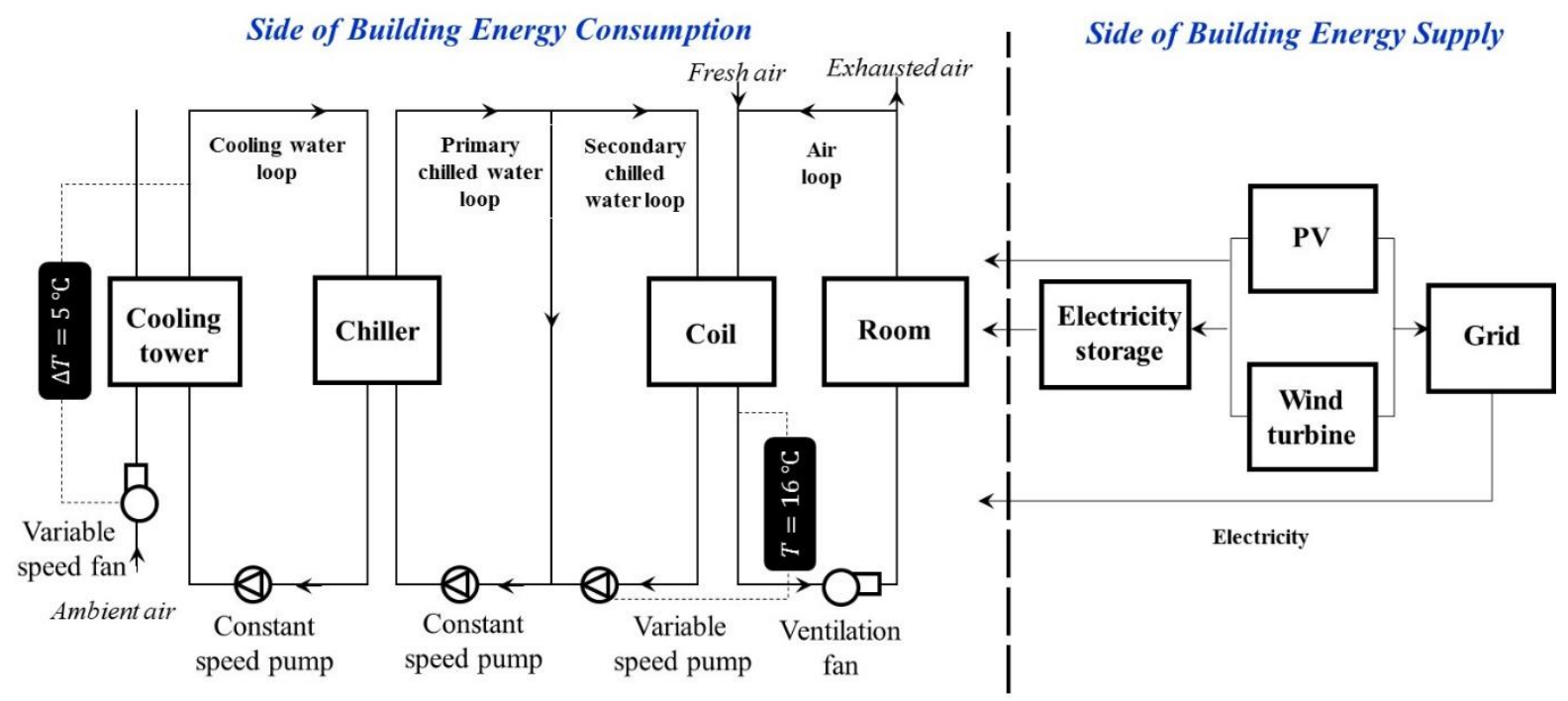

Fig.4. Schematic diagram of the nearly/net ZEB [16, 29, 32].

The hourly-average power generation from PV (Type 562) and WT (Type 90) are estimated by Equations 13 and 14 respectively [70]. Key parameters of PV and WT models are summarized in Table 2.

$$
\operatorname{Pow}_{P V}=S_{p v} \times \tau_{n} \times \alpha_{n} \times(I A M) \times I_{T} \times \eta
$$

where $I A M$ is the overall incidence angle modifier; $I_{T}\left(k W / m^{2}\right)$ is the solar radiation; $\operatorname{Pow}_{P V}(k W)$ is the hourly-average power generation from the installed PV; $S_{p v}\left(\mathrm{~m}^{2}\right)$ is the PV area; $\alpha_{n}$ and $\tau_{n}$ are the absorptance coefficient and transmittance coefficient respectively of the solar radiation normal to PV; and $\eta$ is the overall efficiency of PV.

$$
\operatorname{Pow}_{W T}=S_{W T} \times C_{p} \times \rho \times A_{R} \times v^{3}
$$

where $A_{R}\left(m^{2}\right)$ is the rotor area; $C_{p}\left(\mathrm{~m}^{2} / \mathrm{s}^{2}\right)$ is the function of the axial induction factor; $\operatorname{Pow}_{W T}(k W)$ is the hourly-average power generation from the installed WT; 


\section{Applied Energy}

Volume 228, 15 October 2018, Pages 1020-1031

$S_{W T}$ is the rated power of WT; $\rho\left(\mathrm{kg} / \mathrm{m}^{3}\right)$ is the air density; and $v(\mathrm{~m} / \mathrm{s})$ is the free stream wind speed.

Table 2. Key parameters used in TRNSYS for PV and WT [16, 29, 70].

\begin{tabular}{|l|l|l|l|}
\hline Renewable energy & Parameter & Value & Unit \\
\hline & Back resistance & 1 & $\mathrm{hm}^{2} \mathrm{~K} / \mathrm{kJ}$ \\
\cline { 2 - 4 } & Top emissivity & 0.9 & - \\
\cline { 2 - 4 } $\begin{array}{c}\text { PV } \\
\text { (Type 562) }\end{array}$ & Back emissivity & 0.9 & - \\
\cline { 2 - 4 } & Absorptance & 0.9 & - \\
\cline { 2 - 4 } & Refractive index & 1.526 & - \\
\cline { 2 - 4 } & Cover conductivity & 5.04 & $\mathrm{~kJ} /(\mathrm{hmK})$ \\
\cline { 2 - 4 } & Cover thickness & 0.00635 & $\mathrm{~m}$ \\
\cline { 2 - 4 } & Extinction coefficient & 4 & $\mathrm{~m}{ }^{-1}$ \\
\hline \multirow{5}{*}{$\begin{array}{c}\text { WT } \\
\text { (Type 90) }\end{array}$} & Site elevation & 0 & $\mathrm{~m}$ \\
\cline { 2 - 4 } & Data collection height & 30 & $\mathrm{~m}$ \\
\cline { 2 - 4 } & Turbine power loss & 15 & $\%$ \\
\cline { 2 - 4 } & Rated power & 20 & $\mathrm{~kW}$ \\
\hline
\end{tabular}

The electric storage is operated as follows (Equations 15 to 18 [32]). The surplus energy generation is first stored in the electric storage. After the energy storage is fully charged, the rest electricity is exported to the grid. Conversely, the insufficient energy generation is first complemented by the stored electricity. After the energy storage is fully discharged, the rest energy is imported from the grid.

$$
\Delta E S_{i}= \begin{cases}\min \left(S_{E S}-E S_{\text {store }, i}, \text { Pow }_{\text {mis }}\right) & \text { if Pow } \text { mis } \geq 0 \\ \max \left(-E S_{\text {store }, i}, \text { Pow }_{\text {mis }}\right) & \text { if Pow } \text { mis }_{\text {mis }}<0\end{cases}
$$




$$
\begin{gathered}
E S_{\text {store }, i}=\sum_{n=1}^{i-1} \Delta E S_{n} \\
\text { Pow }_{\text {mis }}=\operatorname{Pow}_{P V, i}+\operatorname{Pow}_{W T, i}-\text { Pow }_{\text {con }, i} \\
E I_{i}=\text { Pow }_{\text {mis }}-\Delta E S_{i}
\end{gathered}
$$

where $E I(k W)$ is the energy interaction between the nearly/net ZEB and grid, and an $E I$ larger than zero means exporting energy; $E S_{\text {store }}(k W h)$ is the electricity stored; Pow $_{c o n}$ is the building hourly-average power consumption; Pow mis $(k W)$ is the mismatch between the building hourly-average power generation and consumption, and a $P o w_{m i s}$ larger than zero means the energy generation is surplus; $\operatorname{Pow}_{P V}(\mathrm{~kW})$ and $\operatorname{Pow}_{W T}(\mathrm{~kW})$ are the building hourly-average power generation from installed PV and WT respectively; $S_{E S}(k W h)$ is the capacity of the electric storage; $\triangle E S(k W)$ is the variation of stored electricity, and a $\Delta E S$ larger than zero means charging electricity; subscripts $i$ and $n$ are the $i^{t h}$ and $n^{\text {th }}$ hour respectively.

Energy consumption components of the HVAC system mainly include a water-cooled chiller (Equation 19), pumps of the cooling water loop and primary and secondary chilled water loops (Equation 20) and fans used in the cooling tower and for room ventilation (Equation 21) [70]. Key parameters of the HVAC model are summarized in Table 3, which are the optimal design results for the studied building from Reference $[25]$.

$$
\text { Pow }_{\text {con,chi }}=\frac{F F L P \times Q_{c}}{C O P_{\text {nom }}}
$$

where $C O P_{n o m}$ is the nominal COP of chiller; FFLP is the fraction of full load power [25]; Pow ${ }_{\text {con,chi }}(k W)$ is the hourly-average power consumption of chiller; $Q_{c}(k W)$ is the cooling capacity of chiller.

$$
\text { Pow }_{\text {con }, \text { pum }}=\frac{\dot{m}_{\text {wat }} \times \Delta P_{\text {wat }}}{\eta_{\text {pum }} \times \rho_{\text {wat }}}
$$

where Pow $_{\text {con,pum }}(k W)$ is the hourly-average power consumption of pumps; $\dot{m}_{\text {wat }}$ $(\mathrm{kg} / \mathrm{s})$ is the water flow rate; $\eta_{\text {pum }}$ is the pump efficiency; $\rho_{\text {wat }}\left(\mathrm{kg} / \mathrm{m}^{3}\right)$ is the water density; $\Delta P_{\text {wat }}(P a)$ is the pressure drop of water flow.

$$
\text { Pow }_{\text {con }, \text { fan }}=\frac{\dot{m}_{\text {air }} \times \Delta P_{\text {air }}}{\eta_{\text {fan }} \times \rho_{\text {air }}}
$$




\section{Applied Energy}

Volume 228, 15 October 2018, Pages 1020-1031

where Pow con,fan $(k W)$ is the hourly-average power consumption of fans; $\dot{m}_{\text {air }}$ $(\mathrm{kg} / \mathrm{s})$ is the air flow rate; $\eta_{\text {fan }}$ is the fan efficiency; $\rho_{\text {air }}\left(\mathrm{kg} / \mathrm{m}^{3}\right)$ is the air density; $\Delta P_{\text {air }}(\mathrm{Pa})$ is the pressure drop of air flow.

Table 3. Key parameters used in TRNSYS for HVAC model [25, 70].

\begin{tabular}{|c|c|c|c|}
\hline Components & Parameter & Value & Unit \\
\hline \multirow{3}{*}{$\begin{array}{c}\text { Chiller } \\
\text { (Type 666) }\end{array}$} & Rated capacity & 195.91 & $\mathrm{~kW}$ \\
\hline & Rated COP & 5.02 & - \\
\hline & $\mathrm{CHW}$ set point temperature & 7 & ${ }^{\circ} \mathrm{C}$ \\
\hline \multirow{3}{*}{$\begin{array}{l}\text { Variable speed Pump } \\
\text { (Type } 741 \text { ) }\end{array}$} & Rated flow rate & 33200 & $\mathrm{~kg} / \mathrm{hr}$ \\
\hline & Overall pump efficiency & 0.6 & - \\
\hline & Motor efficiency & 0.9 & - \\
\hline \multirow{4}{*}{$\begin{array}{l}\text { Constant speed Pump } \\
\text { (Type } 742 \text { ) }\end{array}$} & Inlet fluid flow rate & 33200 & $\mathrm{~kg} / \mathrm{hr}$ \\
\hline & Overall pump efficiency & 0.6 & - \\
\hline & Motor efficiency & 0.9 & - \\
\hline & Pressure drop & 100 & $\mathrm{kPa}$ \\
\hline \multirow{7}{*}{$\begin{array}{l}\text { Cooling tower } \\
\text { (Type 510) }\end{array}$} & Rated fan power & 18450 & $\mathrm{~kJ} / \mathrm{hr}$ \\
\hline & Design fluid flow rate & 55300 & $\mathrm{~kg} / \mathrm{hr}$ \\
\hline & Design air flow rate & 42600 & $\mathrm{~kg} / \mathrm{hr}$ \\
\hline & Design inlet fluid temperature & 32 & ${ }^{\circ} \mathrm{C}$ \\
\hline & Design outlet fluid temperature & 29 & ${ }^{\circ} \mathrm{C}$ \\
\hline & Design ambient air temperature & 35 & ${ }^{\circ} \mathrm{C}$ \\
\hline & Design wet bulb temperature & 25 & ${ }^{\circ} \mathrm{C}$ \\
\hline \multirow{3}{*}{$\begin{array}{l}\text { Ventilation fan } \\
\text { (Type } 744 \text { ) }\end{array}$} & Rated power & 7800 & $\mathrm{~kJ} / \mathrm{hr}$ \\
\hline & Rated flow rate & 77100 & $\mathrm{~kg} / \mathrm{hr}$ \\
\hline & Inlet air humidity & $50 \%$ & - \\
\hline
\end{tabular}




\section{Applied Energy}

Volume 228, 15 October 2018, Pages 1020-1031

\subsection{Determination of design points}

Using the ZEB model (Section 3.1), the maximal and minimal annual energy demands are determined as 283,313 $\mathrm{kWh}$ and 263,516 $\mathrm{kWh}$ respectively (calculated from Equations 4 and 5 with 3 times of the standard deviation respectively). The annual energy generation from PV of one square meter and WT of one kilowatt rated power are $151 \mathrm{kWh}$ and $569 \mathrm{kWh}$ respectively (calculated in a manner similar to Equation 5). The daily energy demand is $1793 \mathrm{kWh}$ (calculated in a manner similar to Equation 4), and thus the minimal and maximal sizes of the electric storage are set to be $897 \mathrm{kWh}$ and $7172 \mathrm{kWh}$ respectively. The design points determined by Box-Behnken design are presented in Table 4 . The central design point is repeated for five times as the default in Design Expert 8.0. There are totally 29 design points (Equation 7).

Table 4. Design points from Box-Behnken design and corresponding sizes of PV, WT and electric storage and confidence level.

\begin{tabular}{|c|c|c|c|c|c|c|c|c|}
\hline $\begin{array}{c}\text { Design } \\
\text { points }\end{array}$ & $\begin{array}{c}\overline{D^{a}} \\
(\text { coded })\end{array}$ & $\begin{array}{c}\bar{\gamma} \\
(\text { coded })\end{array}$ & $\begin{array}{c}\overline{D^{d}} \\
(\text { coded })\end{array}$ & $\begin{array}{c}\bar{l} \\
(\text { coded })\end{array}$ & $\begin{array}{c}\text { PV } \\
\left(m^{2}\right)\end{array}$ & $\begin{array}{c}\text { WT } \\
(k W)\end{array}$ & $\begin{array}{c}\text { Electric } \\
\text { storage } \\
(k W h)\end{array}$ & $\begin{array}{c}\text { Confidence } \\
\text { level } \\
(\%)\end{array}$ \\
\hline 1 & 0 & 0 & 0 & 0 & 904 & 240 & 4034 & 75 \\
\hline 2 & 1 & -1 & 0 & 0 & 0 & 498 & 4034 & 75 \\
\hline 3 & 0 & 1 & 1 & 0 & 1809 & 0 & 7172 & 75 \\
\hline 4 & 0 & 0 & -1 & 1 & 904 & 240 & 897 & 100 \\
\hline 5 & 0 & -1 & 0 & 1 & 0 & 481 & 4034 & 100 \\
\hline 6 & 0 & -1 & 0 & -1 & 0 & 481 & 4034 & 50 \\
\hline 7 & 0 & 0 & 0 & 0 & 904 & 240 & 4034 & 75 \\
\hline 8 & 1 & 0 & 0 & -1 & 937 & 249 & 4034 & 50 \\
\hline 9 & 0 & -1 & -1 & 0 & 0 & 481 & 897 & 75 \\
\hline 10 & 0 & 0 & 1 & 1 & 904 & 240 & 7172 & 100 \\
\hline 11 & -1 & 0 & 1 & 0 & 872 & 232 & 7172 & 75 \\
\hline 12 & 0 & 0 & 0 & 0 & 904 & 240 & 4034 & 75 \\
\hline 13 & 1 & 0 & 1 & 0 & 937 & 249 & 7172 & 75 \\
\hline 14 & -1 & 1 & 0 & 0 & 1743 & 0 & 4034 & 75 \\
\hline 15 & 1 & 0 & -1 & 0 & 937 & 249 & 897 & 75 \\
\hline
\end{tabular}


Applied Energy

Volume 228, 15 October 2018, Pages 1020-1031

\begin{tabular}{|c|c|c|c|c|c|c|c|c|}
\hline 16 & 0 & 1 & -1 & 0 & 1809 & 0 & 897 & 75 \\
\hline 17 & 0 & 1 & 0 & -1 & 1809 & 0 & 4034 & 50 \\
\hline 18 & -1 & 0 & 0 & -1 & 872 & 232 & 4034 & 50 \\
\hline 19 & 1 & 1 & 0 & 0 & 1874 & 0 & 4034 & 75 \\
\hline 20 & -1 & 0 & 0 & 1 & 872 & 232 & 4034 & 100 \\
\hline 21 & -1 & 0 & -1 & 0 & 872 & 232 & 897 & 75 \\
\hline 22 & -1 & -1 & 0 & 0 & 0 & 463 & 4034 & 75 \\
\hline 23 & 0 & -1 & 1 & 0 & 0 & 481 & 7172 & 75 \\
\hline 24 & 0 & 0 & 1 & -1 & 904 & 240 & 7172 & 50 \\
\hline 25 & 1 & 0 & 0 & 1 & 937 & 249 & 4034 & 100 \\
\hline 26 & 0 & 1 & 0 & 1 & 1809 & 0 & 4034 & 100 \\
\hline 27 & 0 & 0 & -1 & -1 & 904 & 240 & 897 & 50 \\
\hline 28 & 0 & 0 & 0 & 0 & 904 & 240 & 4034 & 75 \\
\hline 29 & 0 & 0 & 0 & 0 & 904 & 240 & 4034 & 75 \\
\hline
\end{tabular}

Note: $\overline{D^{a}}$ is the coded annual energy demand (Equation 6); $\bar{\gamma}$ is the coded energy generation percentage of $P V ; \overline{D^{d}}$ is the coded daily energy demand; $\bar{l}$ is the coded confidence level.

\subsection{Development and validation of response surface models}

Equation 22 shows the response surface model of AEMR. The p-values of AEMR model and its terms are less than 0.0001 , indicating that they are statistically significant. The predicted $R^{2}$ of 0.9998 is in reasonable agreement with the adjusted $R^{2}$ of 0.9999. The actual AEMR of the 29 design points runs from $1.3 \%$ to $106.9 \%$ (Figure 5(a)), which is calculated from Monte Carlo simulations (Section 2.3). The lower AEMR is produced when the energy is generated mainly by PV (i.e., $\gamma=100 \%$ ) and the required confidence level is high (e.g., $l=100 \%$ ), due to the more intermittent and uncertain energy generation of PV compared with WT [16]. The deviation between the AEMR predicted by Equation 22 and the actual one is within $-0.6 \% \sim 0.6 \%$. The mean absolute deviation is $0.16 \%$. Equation 23 gives the response surface model of SCR. The p-values of SCR model and its terms are less than 0.039 , indicating that they are statistically significant. The predicted $R^{2}$ of 0.9693 is also in reasonable agreement with the adjusted $R^{2}$ of 0.9869 . The actual SCR of the 29 design points runs from $69.1 \%$ to $100 \%$ (Figure 5(b)), which is calculated by Monte Carlo simulations (Section 2.3). The smaller variation range of SCR compared with that of AEMR demonstrates the 
Applied Energy

Volume 228, 15 October 2018, Pages 1020-1031

effectiveness of the electric storage for mitigating the imbalance between the building energy generation and consumption. The deviation between SCR predicted by Equation 23 and the actual one is within $-2.0 \% \sim 2.0 \%$. The mean absolute deviation is $0.63 \%$.

$$
A E M R=1.88 \bar{D}^{a}-50.65 \bar{\gamma}-1.40 \bar{l}-1.84 \overline{D^{a}} \bar{\gamma}+1.38 \bar{\gamma} \bar{l}-0.84 \bar{l}^{2}+52.25
$$

$S C R=11.10 \bar{\gamma}+3.87 \overline{D^{d}}-1.79 \bar{l}-3.32 \bar{\gamma} \overline{D^{d}}+1.08 \bar{\gamma} \bar{l}-6.19 \bar{\gamma}^{2}-2.12 \bar{D}^{d^{2}}-1.33 \bar{l}^{2}+96.24$

where $A E M R(\%)$ is the annual energy match ratio; SCR $(\%)$ is the self-consumption ratio; $\overline{D^{a}}$ is the coded annual energy demand; $\overline{D^{d}}$ is the coded daily energy demand; $\bar{l}$ is the coded confidence level; $\bar{\gamma}$ is the coded energy generation percentage of PV.

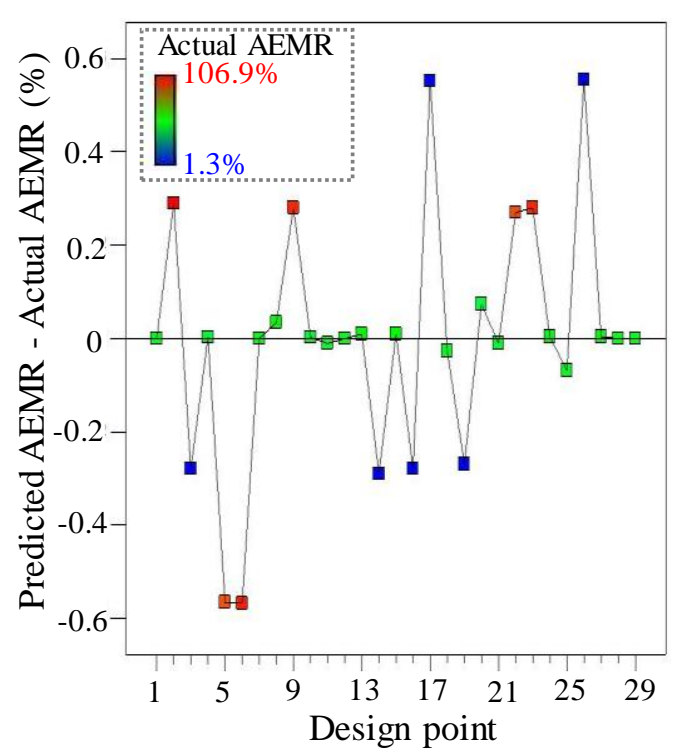

(a)

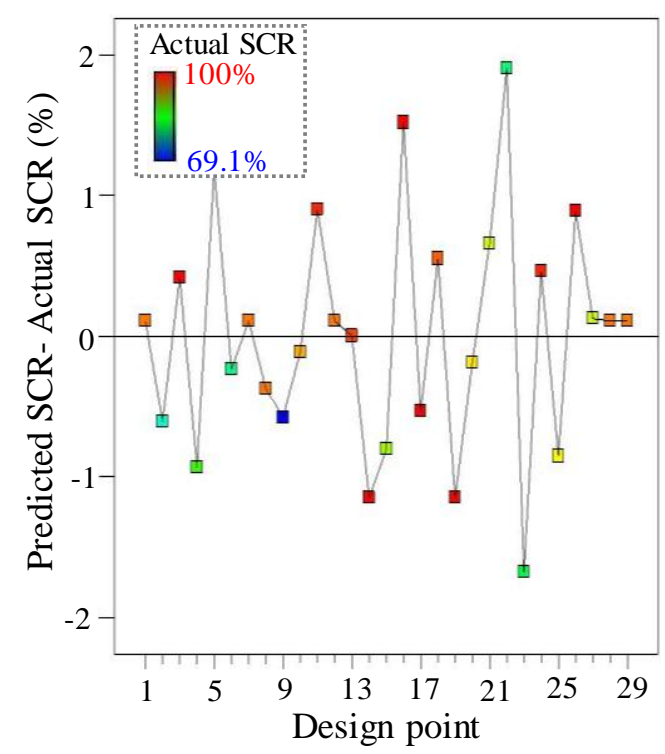

(b)

Note: The 29 design points are used for establishment of response surface models.

Fig.5. Deviations between values predicted by response surface models and actual values calculated by Monte Carlo simulations: (a) Annual energy match ratio (AEMR) and (b) self-consumption ratio (SCR).

The response surface models are validated further by compared with the actual results of design points independent from the model establishment. 1296 different design points are selected (i.e., 1296 combinations of six different annual energy demands, six different energy generation percentages of PV, six different daily energy demands and six different confidence levels). The six annual energy demands $\left(\overline{D^{a}} k W h\right)$ increase from the minimal annual energy demand (i.e., $\left.D_{\min }^{a} k W h\right)$ to the maximal one (i.e., 
Applied Energy

Volume 228, 15 October 2018, Pages 1020-1031

$\left.D_{\max }^{a} k W h\right)$ with an equal interval of $20 \%$. So do the six energy generation percentages of PV $(\bar{\gamma} \%)$, six daily energy demands $\left(\overline{D^{d}} k W h\right)$ and six confidence levels $(\bar{l} \%)$. The 1296 design points are filtered that AEMR and SCR should be larger than $20 \%$ and $50 \%$ respectively, and 1080 design points remain. An excessively small AEMR is far beyond the requirements of a nearly/net ZEB and an excessively small SCR led to heavy grid stress $[1,19]$.

Figure 6 shows that both the predicted AEMR and SCR of the 1080 design points are almost of the diagonal function of $y=x$ with the actual values. This indicates that the predicted values of AEMR and SCR from the response surface models are quite close to the actual values. Moreover, Figure 7 shows the histogram and cumulative probability of the discrepancy between the predicted and actual values (Equation 24). The absolute discrepancy of AEMR is less than $1.5 \%$ with a cumulative probability of $95 \%$. The expected value of the absolute discrepancy is $0.6 \%$. With regards to SCR, the absolute discrepancy is less than $3.5 \%$ with a cumulative probability of $95 \%$, and is $1.2 \%$ in expectation. Therefore, the response surface models of AEMR and SCR are credible.

$$
\text { Discrepancy }=\frac{\text { predicted value }- \text { actual value }}{\text { actual value }} \times 100 \%
$$

where predicted value is from the proposed method; actual value is calculated by Monte Carlo simulations.

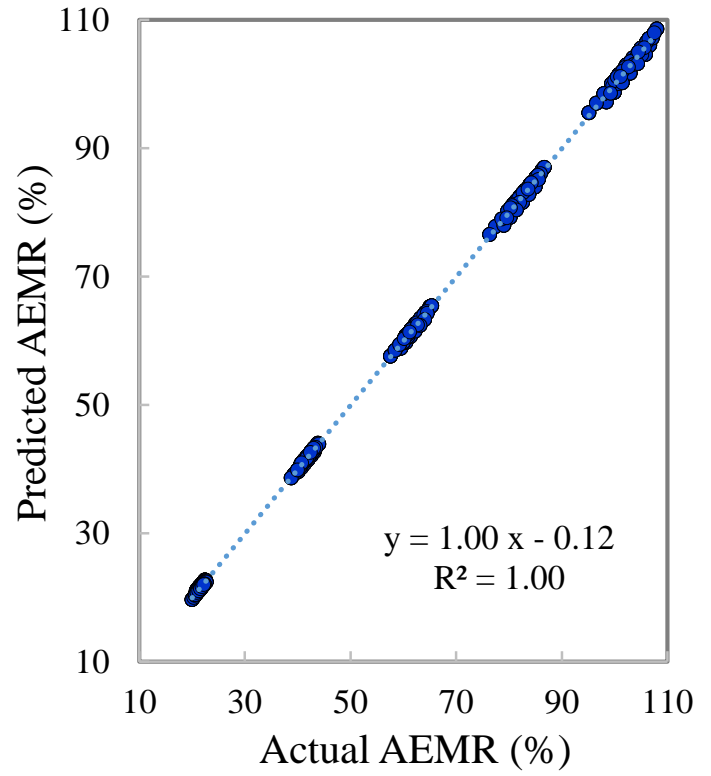

(a)

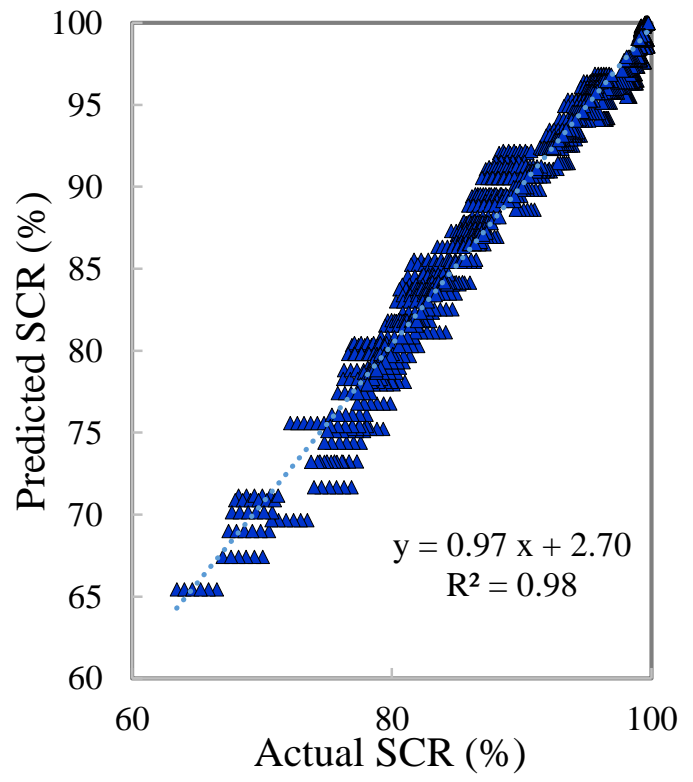

(b) 
Note: The included 1080 design points are not involved in the establishment of the response surface models.

Fig.6. Comparisons between values predicted by response surface models and actual values calculated by Monte Carlo simulations: (a) Annual energy match ratio (AEMR) and (b) self-consumption ratio (SCR).

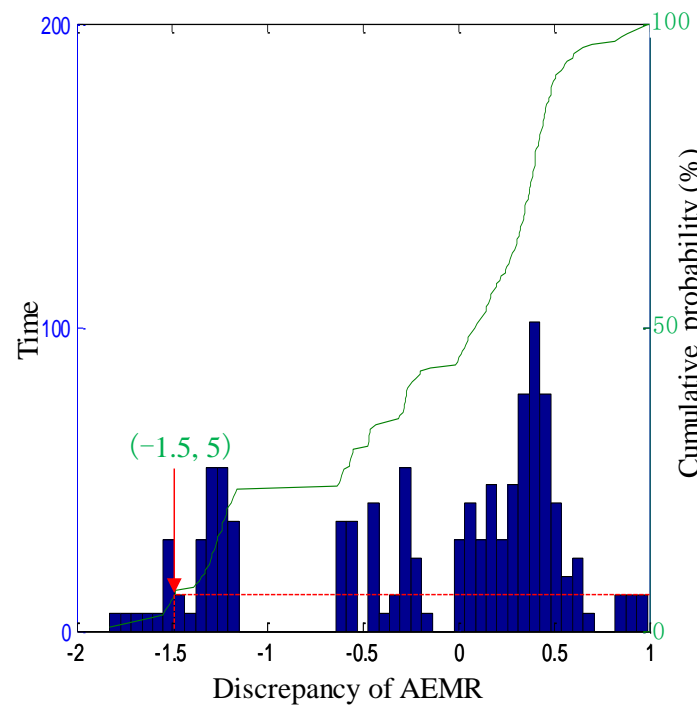

(a)

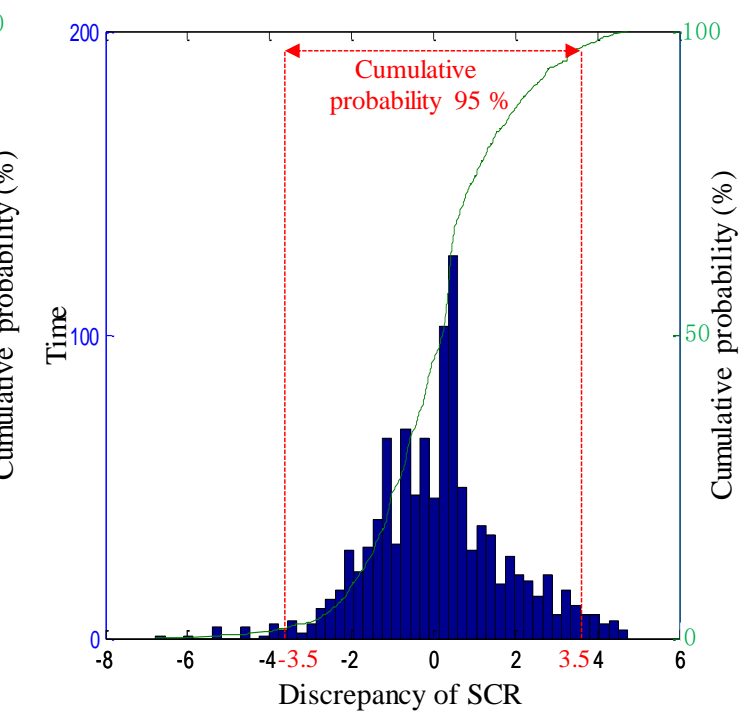

(b)

Note: The included 1080 design points are not involved in the establishment of the response surface models; the discrepancy is calculated by Equation 24.

Fig.7. Histogram and cumulative probability of discrepancy between values predicted by response surface models and actual values calculated by Monte Carlo simulations: (a) Annual energy match ratio (AEMR) and (b) self-consumption ratio (SCR).

\subsection{Validation of proposed method for system sizing}

Due to the discrepancies between the predicted AEMR and SCR by the response surface models and the actual values calculated by Monte Carlo simulations (Figures 5-7), the overall performances of the design options calculated by the proposed method might deviate from the actual overall performances calculated by Monte Carlo simulations. 
Applied Energy

Volume 228, 15 October 2018, Pages 1020-1031

As a result, the proposed method might not sort out the optimal design option. The overall performance (Equation 12) of the selected design option by the proposed method and that of the optimal design option are firstly compared. 1331 different design options are considered (11 different sizes of PV, WT and the electric storage respectively with an equal interval of $10 \%$ from the minimal value to the maximal value, i.e., $n_{1}=n_{2}=n_{3}=11$ in Figure 1). Therefore, compared with conducting Monte Carlos simulations for all design options, the proposed method reduces the number of Monte Carlo simulations by $97.8 \%$ (from 1331 to 29 ).

10,000 different decision scenarios are included. That is, 10,000 different combinations of users' preferences towards the confidence levels, constraints and weighting factors of AEMR, SCR and initial investment. The users' preferences are randomly produced with a uniform distribution. The confidence levels are limited within 50\% 100\% considering the robustness of the selected design option [15, 32]. The constraints are that AEMR is larger than 50\% 100\% [15] and SCR is larger than 60\% 80\% [17, 19]. For all the 10,000 decision scenarios, the overall performance of the selected design option by the proposed method is quite similar to that of the optimal design option, with almost a diagonal function of $y=x$ between them (Figure 8(a)). This can be explained by the credible response surface models (Section 3.3). Figure 8(b) shows that the discrepancy of overall performances (Equation 24) between the selected design option by the proposed method and the optimal design option is $-2.0 \%$ in expectation, and larger than $-8.7 \%$ with a cumulative probability of $95 \%$. In other words, the overall performance of the proposed method is slightly deteriorated by $2.0 \%$ in expectation, and the overall performance deterioration is less than $8.7 \%$ with a cumulative probability of $95 \%$. 
Volume 228, 15 October 2018, Pages 1020-1031

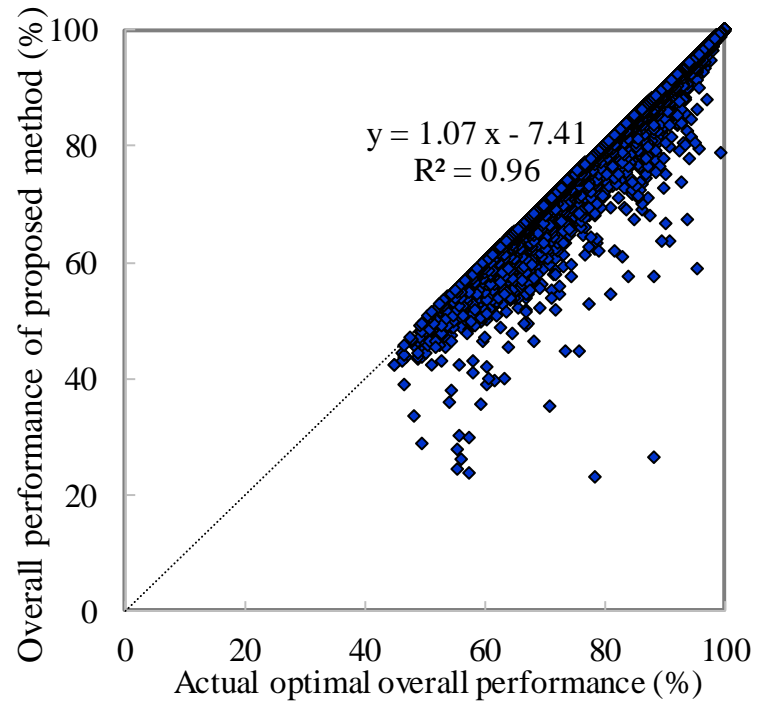

(a)

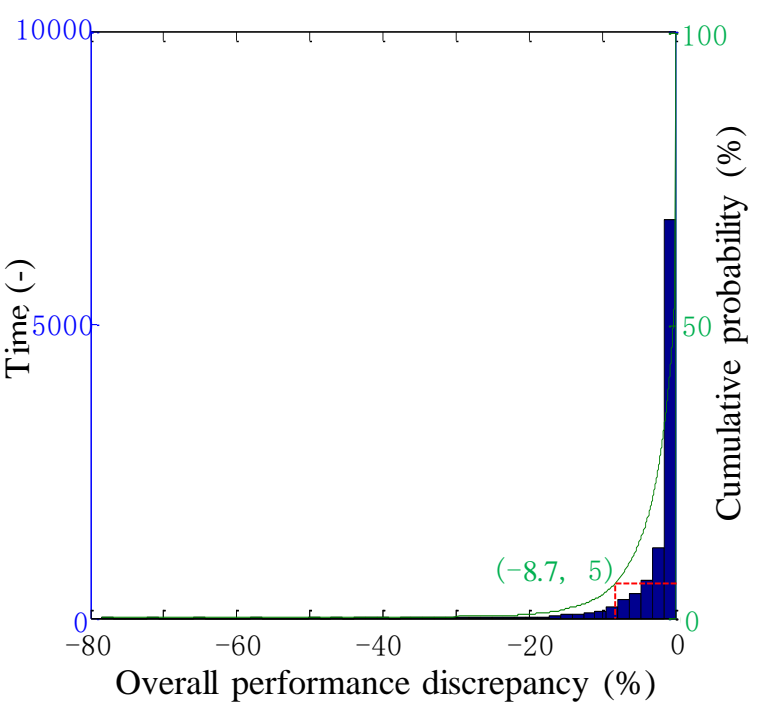

(b)

Note: Overall performance discrepancy is the calculated by Equation 24, and 10,000 different decision scenarios are considered.

Fig.8. (a) Comparisons of overall performances and (b) histogram and cumulative probability of overall performance discrepancy: Design option selected by proposed method and actual optimal design option.

The rank of selected design option by the proposed method among the 1331 different design options is further investigated for the 10,000 different decision scenarios (Figure 9). Rank $0 \%$ indicates that the selected design option by the proposed method is the best one among the 1331 design options. It is seen that the proposed method can sort out top $1.1 \%$ design option in expectation, and top $5.6 \%$ design option with a cumulative probability of $95 \%$. Therefore, the proposed method largely reduces the number of Monte Caro simulations by $97.8 \%$ (from 1331 to 29), and robustly sorts out the optimal design option in the statistical sense. 
Applied Energy

Volume 228, 15 October 2018, Pages 1020-1031

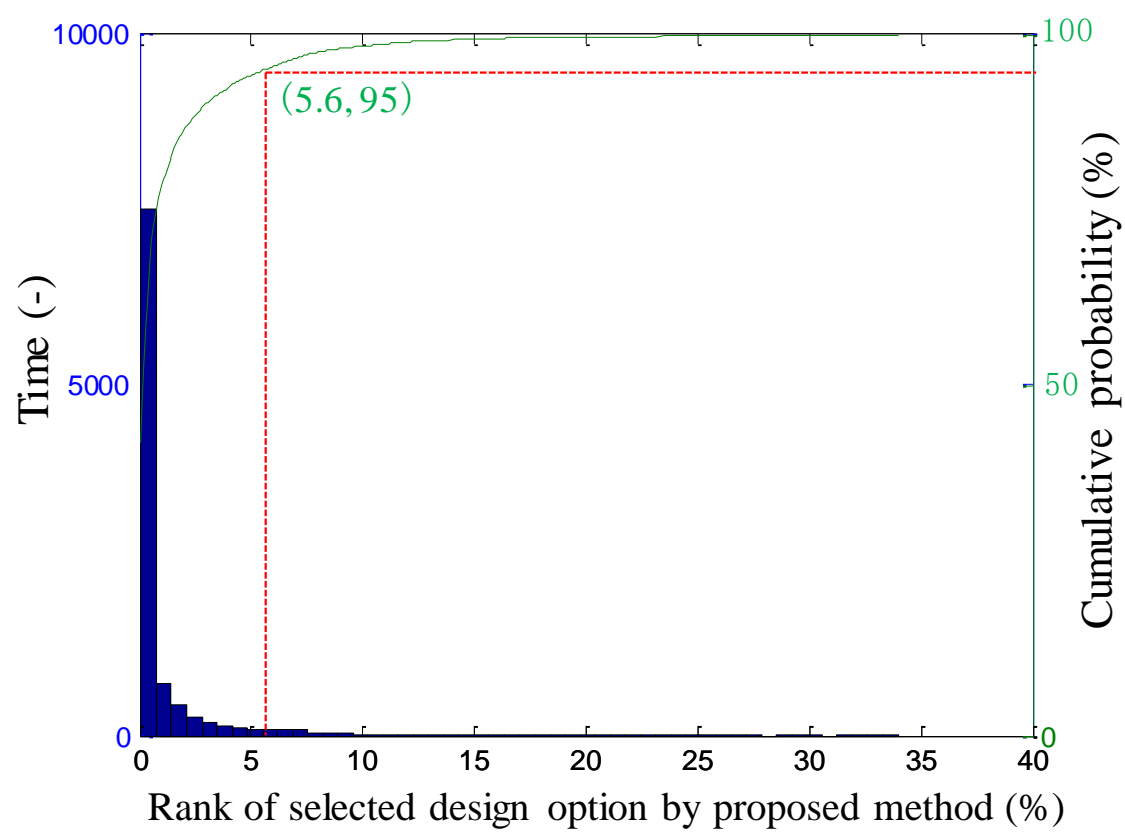

Note: Rank $0 \%$ indicates that the selected design option by the proposed method is the best one among the 1331 design options, and 10,000 different decision scenarios are considered.

Fig.9. Rank of design option selected by proposed method.

\section{Discussion}

This study also supports the usage of the proposed method for sizing the energy consumption system (e.g., HVAC [32]) for nearly/net ZEBs. The proposed method could accurately predict AEMR and SCR based on the building energy generation and consumption (Section 3.3), indicating that the proposed method could accurately predict the building energy consumption. The accurately predicted building energy consumption could be used as the basis for sizing the energy consumption system [73]. Moreover, the proposed method is applicable not only to nearly/net ZEBs which are connected to the grid, but also to standalone ZEBs which are off-grid (e.g., in remote areas without access to the grid) [4]. For standalone ZEBs, the constraints on AEMR and SCR are both set to $100 \%$ (Figure 1), so that the buildings could generate sufficient energy for the annual energy consumption and all the generated energy is consumed by 
Applied Energy

Volume 228, 15 October 2018, Pages 1020-1031

the buildings without import/export of energy from/to the grid.

The overall performance of the proposed method could be enhanced further by improving the accuracy of response surface models. The accuracy of the response surface models could be increased by optimizing the Design of Experiment methods. In this study, only Box-Behnken design is considered. There are many other methods for Design of Experiment, e.g., central composite design and spacing filling design [39, 74]. Optimizing the Design of Experiment methods could optimally determine the design points to obtain response surface models with the highest accuracy [39]. The performance of Design of Experiment methods may vary among research areas [36], and the optimal Design of Experiment method for ZEBs needs to be identified in future.

In real applications, the detailed processes of the proposed method should be followed (Section 3). It is noted that the design criteria considered in this study are the most widely used ones for nearly/net ZEBs, but other design criteria might be included (e.g., embodied energy balance and $\mathrm{CO}_{2}$ emission balance regarding the life cycle performance $[4,75])$. Furthermore, the statistical distributions of parameters in Table 1 can be replaced by the specific data of the real application if available. The parameter uncertainties included in this study cover most of those significantly affecting the building energy generation and consumption [16, 25, 29, 56-67], but more parameter uncertainties (e.g., capacity degradation and cooling loss of HVAC [76]) can also be incorporated if they are of particular concerns in the future applications.

\section{Conclusions}

This study proposes a response-surface-model-based system sizing method for nearly/net ZEBs under uncertainty. Firstly, response surface models of the design criteria are established based on Monte Carlo simulations for 29 design points. The design criteria include AEMR, SCR and initial investment, and the 29 design points are 
Applied Energy

Volume 228, 15 October 2018, Pages 1020-1031

determined by Box-Behnken design. Secondly, using the established response surface models, the overall performances (i.e., the weighted performance of design criteria) of all design options are evaluated. Finally, the design option with the maximal overall performance is selected as the optimal one. Without the proposed method, Monte Carlo simulations are required for thousands of possible design options to identify the optimal design option, which leads to computational load that is heavy or even impossible to handle in practice. Thus, the proposed method can substantially reduce the number of Monte Carlo simulations.

Cases studies on the sizing of PV, WT and electricity storage for a nearly/net ZEB show that the established response surface models of AEMR and SCR are fairly close to the actual values calculated by Monte Carlo simulations. The errors in the predicted AEMR and SCR by the response surface models are $0.6 \%$ and $1.2 \%$ in expectation respectively. The validated response surface models are used to evaluate the overall performances of 1331 design options of PV, WT and electric storage under 10,000 decision scenarios (i.e., users' preferences to the confidence levels, constraints and weighting factors of AEMR, SCR and initial investment). The proposed method significantly reduces the Monte Carlo simulations by $97.8 \%$, and robustly sorts out top $5.6 \%$ design option with a cumulative probability of $95 \%$ and top $1.1 \%$ design option in expectation.

With the significantly reduced Monte Carlo simulations and high rank of the selected design option, the proposed method provides system designers a practical and efficient means for system sizing of nearly/net ZEBs under uncertainty.

\section{Acknowledgment}

The work described in this paper is supported by a General Research Grant from the Research Grants Council of the Hong Kong Special Administrative Region, China (Project No. CityU 11210617), and the Fundamental Research Funds for the Central 
Applied Energy

Volume 228, 15 October 2018, Pages 1020-1031

Universities (Project No. 2018CDXYCH0015).

\section{Reference}

[1] Li DH, Yang L, Lam JC. Zero energy buildings and sustainable development implications-A review. Energy 2013; 54:1-10.

[2] Seljom P, Lindberg KB, Tomasgard A, Doorman G, Sartori I. The impact of Zero Energy Buildings on the Scandinavian energy system. Energy 2017, 118, 284-296.

[3] IEA, IEA Statistics: World Energy Statistics and Balances, http://www.iea.org/statistics-/topics/energybalances/, 2014.

[4] Marszal AJ, Heiselberg P, Bourrelle JS, Musall E, Voss K, Sartori I, Napolitano A. Zero Energy Building-A review of definitions and calculation methodologies. Energy and buildings 2011; 43(4):971-979.

[5] Sartori I, Napolitano A, Voss K. Net zero energy buildings: A consistent definition framework. Energy and buildings 2012; 48:220-232.

[6] Wu W, Skye HM, Domanski PA. Selecting HVAC systems to achieve comfortable and cost-effective residential net-zero energy buildings. Applied Energy 2018; 212:577-591.

[7] Liu Z, Xu W, Qian C, Chen X, Jin G. Investigation on the feasibility and performance of ground source heat pump (GSHP) in three cities in cold climate zone, China. Renewable Energy 2015; 84:89-96.

[8] He Y, Sun Y, Zhang S, Lyu Y, Chen G. Initial ratio optimization for the ejector cooling system with thermal pumping effect (ECSTPE). Energy Conversion and Management 2016; 113:281-289.

[9] AlAjmi A, Abou-Ziyan H, Ghoneim A. Achieving annual and monthly net-zero energy of existing building in hot climate. Applied Energy 2016; 165:511-521.

[10]Mohamed A, Hasan A, Sirén K. Fulfillment of net-zero energy building (NZEB) with four metrics in a single family house with different heating alternatives. Applied Energy 2014; 114:385-399. 
Applied Energy

Volume 228, 15 October 2018, Pages 1020-1031

[11] Salom J, Marszal AJ, Widén J, Candanedo J, Lindberg KB. Analysis of load match and grid interaction indicators in net zero energy buildings with simulated and monitored data. Applied Energy 2014; 136:119-131.

[12]Deng S, Wang RZ, Dai YJ. How to evaluate performance of net zero energy building-A literature research. Energy 2014; 71:1-16.

[13]Congedo PM, Baglivo C, D'Agostino D, Zacà I. Cost-optimal design for nearly zero energy office buildings located in warm climates. Energy 2015; 91:967-982.

[14]Lu Y, Wang S, Shan K. Design optimization and optimal control of grid-connected and standalone nearly/net zero energy buildings. Applied Energy 2015; 155:463477.

[15]Lu Y, Wang S, Yan C, Huang Z. Robust optimal design of renewable energy system in nearly/net zero energy buildings under uncertainties. Applied Energy 2017; 187:62-71.

[16]Zhang S, Huang P, Sun Y. A multi-criterion renewable energy system design optimization for net zero energy buildings under uncertainties. Energy 2016; 94:654-665.

[17]Baetens R, De Coninck R, Van Roy J, Verbruggen B, Driesen J, Helsen L, Saelens D. Assessing electrical bottlenecks at feeder level for residential net zero-energy buildings by integrated system simulation. Applied Energy 2012; 96:74-83.

[18]Nielsen S, Möller B. Excess heat production of future net zero energy buildings within district heating areas in Denmark. Energy 2012; 48(1):23-31.

[19] Vieira FM, Moura PS, de Almeida AT. Energy storage system for self-consumption of photovoltaic energy in residential zero energy buildings. Renewable Energy 2017; 103:308-320.

[20]Castillo-Cagigal M, Caamano-Martín E, Matallanas E, Masa-Bote D, Gutiérrez A, Monasterio-Huelin F, Jiménez-Leube J. PV self-consumption optimization with storage and active DSM for the residential sector. Solar Energy 2011; 85(9):23382348. 
Applied Energy

Volume 228, 15 October 2018, Pages 1020-1031

[21]Beck T, Kondziella H, Huard G, Bruckner T. Optimal operation, configuration and sizing of generation and storage technologies for residential heat pump systems in the spotlight of self-consumption of photovoltaic electricity. Applied Energy 2017; 188:604-619.

[22]Lu Y, Wang S, Zhao Y, Yan C. Renewable energy system optimization of low/zero energy buildings using single-objective and multi-objective optimization methods. Energy and Buildings 2015; 89:61-75.

[23]D'Agostino D, Parker D. A framework for the cost-optimal design of nearly zero energy buildings (NZEBs) in representative climates across Europe. Energy 2018; 149:814-829.

[24]Celik AN. Techno-economic analysis of autonomous PV-wind hybrid energy systems using different sizing methods. Energy Conversion and Management 2003; 44(12):1951-1968.

[25]Huang P, Huang G, Wang Y. HVAC system design under peak load prediction uncertainty using multiple-criterion decision making technique. Energy and Buildings 2015; 91:26-36.

[26]Lu Y, Wang S, Yan C, Shan K. Impacts of renewable energy system design inputs on the performance robustness of net zero energy buildings. Energy 2015; 93:15951606.

[27] Gang W, Wang S, Shan K, Gao D. Impacts of cooling load calculation uncertainties on the design optimization of building cooling systems. Energy and Buildings 2015; 94:1-9.

[28] Shen L, Sun Y. Performance comparisons of two system sizing approaches for net zero energy building clusters under uncertainties. Energy and Buildings 2016; 127:10-21.

[29] Sun Y, Huang P, Huang G. A multi-criteria system design optimization for net zero energy buildings under uncertainties. Energy and Buildings 2015; 97:196-204.

[30]Zhou Z, Feng L, Zhang S, Wang C, Chen G, Du T, Li Y, Zuo J. The operational 
Applied Energy

Volume 228, 15 October 2018, Pages 1020-1031

performance of "net zero energy building": A study in China. Applied energy 2016; 177:716-728.

[31] Attia S, Eleftheriou P, Xeni F, Morlot R, Ménézo C, Kostopoulos V, Betsi M, Kalaitzoglou I, Pagliano L, Cellura M, Almeida M, Ferreira M, Baracu T, Badescu V, Crutescu R, Hidalgo-Betanzos JM. Overview and future challenges of nearly zero energy buildings (nZEB) design in Southern Europe. Energy and Buildings $2017 ; 155: 439-458$.

[32] Yu ZJ, Chen J, Sun Y, Zhang G. A GA-based system sizing method for net-zero energy buildings considering multi-criteria performance requirements under parameter uncertainties. Energy and Buildings 2016; 129:524-534.

[33]Tian W, Heo Y, de Wilde P, Li Z, Yan D, Park CS, Feng X, Augenbroe G. A review of uncertainty analysis in building energy assessment. Renewable and Sustainable Energy Reviews 2018; 93:285-301.

[34]Garshasbi S, Kurnitski J, Mohammadi Y. A hybrid Genetic Algorithm and Monte Carlo simulation approach to predict hourly energy consumption and generation by a cluster of Net Zero Energy Buildings. Applied Energy 2016; 179:626-637.

[35]Huang P, Huang G, Sun, Y. Uncertainty-based life-cycle analysis of near-zero energy buildings for performance improvements. Applied Energy 2018; 213:486498.

[36] Shen X, Zhang G, Bjerg B. Assessments of experimental designs in response surface modelling process: Estimating ventilation rate in naturally ventilated livestock buildings. Energy and Buildings 2013; 62:570-580.

[37]Geyer P, Schlüter A. Automated metamodel generation for Design Space Exploration and decision-making-A novel method supporting performanceoriented building design and retrofitting. Applied Energy 2014; 119:537-556.

[38]Norton T, Grant J, Fallon R, Sun DW. Optimising the ventilation configuration of naturally ventilated livestock buildings for improved indoor environmental homogeneity. Building and Environment 2010; 45(4):983-995. 
Applied Energy

Volume 228, 15 October 2018, Pages 1020-1031

[39]Shen X, Zhang G, Bjerg B. Investigation of response surface methodology for modelling ventilation rate of a naturally ventilated building. Building and Environment 2012; 54:174-185.

[40]Zhou L, Haghighat F. Optimization of ventilation system design and operation in office environment, Part I: Methodology. Building and Environment 2009; 44(4):651-656.

[41]Chen H, Moshfegh B, Cehlin M. Computational investigation on the factors influencing thermal comfort for impinging jet ventilation. Building and Environment 2013; 66:29-41.

[42]Cetin KS, Manuel L, Novoselac A. Thermal comfort evaluation for mechanically conditioned buildings using response surfaces in an uncertainty analysis framework. Science and Technology for the Built Environment 2016; 22(2):140152.

[43]Cetin KS, Manuel L, Novoselac A. Effect of technology-enabled time-of-use energy pricing on thermal comfort and energy use in mechanically-conditioned residential buildings in cooling dominated climates. Building and Environment 2016; 96:118-130.

[44]Robertson JJ, Polly BJ, Collis JM. Reduced-order modeling and simulated annealing optimization for efficient residential building utility bill calibration. Applied Energy 2015; 148:169-177.

[45]Hiyama K, Wen L. Rapid response surface creation method to optimize window geometry using dynamic daylighting simulation and energy simulation. Energy and Buildings 2015; 107:417-423.

[46] Singh K, Das R. Exergy optimization of cooling tower for HGSHP and HVAC applications. Energy Conversion and Management 2017; 136:418-430.

[47] Kim W, Jeon SW, Kim Y. Model-based multi-objective optimal control of a VRF (variable refrigerant flow) combined system with DOAS (dedicated outdoor air system) using genetic algorithm under heating conditions. Energy 2016; 107:196- 
Applied Energy

Volume 228, 15 October 2018, Pages 1020-1031

204.

[48]Kneifel J, Webb D. Predicting energy performance of a net-zero energy building: A statistical approach. Applied energy 2016; 178:468-483.

[49] Guarino F, Cassarà P, Longo S, Cellura M, Ferro E. Load match optimisation of a residential building case study: A cross-entropy based electricity storage sizing algorithm. Applied energy 2015; 154:380-391.

[50]Mäkelä M. Experimental design and response surface methodology in energy applications: a tutorial review. Energy Conversion and Management 2017; 151: 630-640.

[51]Mao N, Zhang B, Song M, Deng S. A simplified numerical study on the energy performance and thermal environment of a bedroom TAC system. Energy and Buildings 2018; 166:305-316.

[52]Design Expert Version 8.0.6. User's Guide. Stat-Ease Inc, USA.

[53] Anderson MJ, Whitcomb PJ. RSM simplified: optimizing processes using response surface methods for design of experiments. CSC Press, New York, 2004.

[54]Barton JP, Infield DG. Energy storage and its use with intermittent renewable energy. IEEE transactions on energy conversion 2004; 19(2):441-448.

[55]Diaf S, Belhamel M, Haddadi M, Louche A. Technical and economic assessment of hybrid photovoltaic/wind system with battery storage in Corsica island. Energy Policy 2008; 36(2):743-754.

[56]Elhadidy MA, Shaahid SM. Optimal sizing of battery storage for hybrid (wind+ diesel) power systems. Renewable Energy 1999; 18(1):77-86.

[57]Hopfe CJ. Uncertainty and sensitivity analysis in building performance simulation for decision support and design optimization. PhD diss., Eindhoven University, 2009.

[58]Boyle G. Renewable energy. Oxford University Press, 2004.

[59]Myers DR. Solar radiation modeling and measurements for renewable energy applications: data and model quality. Energy 2005; 30(9):1517-1531. 
Applied Energy

Volume 228, 15 October 2018, Pages 1020-1031

[60]Atwa YM, El-Saadany EF, Salama MMA, Seethapathy R. Optimal renewable resources mix for distribution system energy loss minimization. IEEE Transactions on Power Systems 2010; 25(1):360-370.

[61]Sun C, Bie Z, Xie M, Ning G. Effects of wind speed probabilistic and possibilistic uncertainties on generation system adequacy. IET Generation, Transmission \& Distribution 2014; 9(4):339-347.

[62]Falconett I, Nagasaka K. Comparative analysis of support mechanisms for renewable energy technologies using probability distributions. Renewable Energy 2010; 35(6):1135-1144.

[63]Domínguez-Muñoz F, Anderson B, Cejudo-López JM, Carrillo-Andrés A. Uncertainty in the thermal conductivity of insulation materials. Energy and Buildings 2010; 42(11):2159-2168.

[64]ASHRAE. ASHRAE handbook - fundamentals. ASHRAE Inc., Atlanta, USA, 2009.

[65]Macdonald IA. Quantifying the effects of uncertainty in building simulation. University of Strathclyde, 2002.

[66]Hopfe CJ, Hensen JL. Uncertainty analysis in building performance simulation for design support. Energy and Buildings 2011; 43(10):2798-2805.

[67]Lomas KJ, Eppel H. Sensitivity analysis techniques for building thermal simulation programs. Energy and buildings 1992; 19(1):21-44.

[68]Box GE, Hunter WG, Hunter JS. Statistics for experimenters: an introduction to design, data analysis, and model building (Vol. 1). New York, Wiley, 1978.

[69]Huang P, Huang G, Augenbroe G. Sizing heating, ventilating, and air-conditioning systems under uncertainty in both load-demand and capacity-supply side from a life-cycle aspect. Science and Technology for the Built Environment 2017; $23(2): 367-381$.

[70]Klein SA. TRNSYS 16 program manual. Madison, Madison, USA: Solar Energy Laboratory, University of Wisconsin, 2007. 
Applied Energy

Volume 228, 15 October 2018, Pages 1020-1031

[71]Zhang S, Cheng Y, Fang Z, Huan C, Lin Z. 2017. Optimization of room air temperature in stratum-ventilated rooms for both thermal comfort and energy saving. Applied Energy, 204, 420-431.

[72]Cheng Y, Lin Z. Experimental study of airflow characteristics of stratum ventilation in a multi - occupant room with comparison to mixing ventilation and displacement ventilation. Indoor air 2015; 25(6):662-671.

[73]Dhariwal J, Banerjee R. An approach for building design optimization using design of experiments. Building Simulation 2017; 10(3):1-14.

[74] Sofotasiou P, Calautit JK, Hughes BR, O'Connor D. Towards an integrated computational method to determine internal spaces for optimum environmental conditions. Computers \& Fluids 2016; 127:146-160.

[75]Fong ML, Lin Z, Fong KF, Hanby V, Greenough R. Life cycle assessment for three ventilation methods. Building and Environment 2017; 116:73-88.

[76]Huang P, Huang G, Augenbroe G, Li S. Optimal configuration of multiple-chiller plants under cooling load uncertainty for different climate effects and building types. Energy and Buildings 2018; 158:684-697. 